\title{
Comparing ourselves: using benchmarking techniques to measure performance between academic libraries
}

\section{Report of the LIRG seminar: The Effective academic library held on Tuesday $12^{\text {th }}$ June 2001 at Staffordshire University}

\section{Liz Hart}

\section{The author}

Liz Hart is the Director of Library and Learning Resources Service at Staffordshire University and a LIRG Committee member

\section{Introduction}

We can learn a lot from others. Benchmarking provides a structural framework for making comparisons with other organisations. The techniques enable us to learn from one another by looking at why there are differences in performance outcomes between organisations undertaking similar functions. This seminar concentrated on:-

- Importance of benchmarking / benchmarking techniques

- Establishment of benchmarking consortia

- Utilising statistics and performance indicators

- Practical examples of how academic libraries have evaluated and improved their services through benchmarking

The seminar opened with a brief welcome from Liz Hart, Director of Library and Learning Resources, on behalf of LIRG and Staffordshire University

\section{Importance of Benchmarking and benchmarking Consortia to Universities}

\section{Ken Sproston, University Secretary and Deputy Vice-Chancellor, Staffordshire} University.

Ken Sproston provided an overview of the importance of benchmarking to the academic sector. He commenced with a brief outline of requirements for successful benchmarking:-

- Commitment of partners

- Co-operation of partners and their willingness to openly share information and data

- Compatibility of partners

- Willingness to learn and accept need for change

- Staff time involved

- Understanding of benchmarking and the need for confidential

He further outlined a benchmarking initiative within the Higher Education (HE) sector between 12 institutions co-ordinated by consultants Ben Johnson-Hill Associates. The proposed project would create a Benchmarking club. "The club would provide a forum for comparing and contrasting financial and other management information in 
order to improve effectiveness and value for money and develop management and operational best practice". The project proposed to share information as follows:

Financial and performance management

- Staff costs / numbers

- Income sources

- Support / service functions / visits

- Cost and use of space

- Research

- Commercial activities

- Conference activities

Sharing of good practice

- Resource allocation models

- Reviews of processes / operations

- Management and organisational structures

- Performance and quality indicators

- Activity based costing

- Change management

The project was still in the developmental stage but could prove very worthwhile if the appropriate agreements were put in place.

Ken continued with an outline of two initiatives from within Staffordshire University based around the Strategic need to "re-egress the University". These were called Building the Learning Community (BLC) and Process Improvement Programme (PIP).

The BLC initiative was a long-term strategy within the following remit:

- To find ways to improve student learning

- To respond to resources pressures by finding move efficient ways to deliver learning

- To free staff time to engage with new ideas

- To see how new technologies could help us to achieve our aims

The core of the development strategies was the creation of the Learning Development Centre in 1997/98.

The PIP initiative was based around a small core team of staff whose main role was to stimulate and co-ordinate developments within Schools/Faculties and Services. It had centred around four core administrative processes:-

- Management of student information;

- Management of student acquisition (recruitment and retention)

- Management of student learning;

- Management of the student experience.

Key changes and improvements over the last three years included:- 
- Creation of a new computerised student information system (TheSIS - The Student Information System)

- All staff and students on email

- Most staff and student information available in electronic form

- Creation of PIP teams to all Schools / Faculties and Services

- One-stop-shop Student Information Centres and a network of information kiosks.

Ken closed his presentation with a re-affirmation of his firm beliefs in the strategic relevance of benchmarking and performance measurement to Universities today.

\section{Benchmarking Academic Library Services}

Stephen Town, Director of Information Services, Royal Military College of Science and Deputy University Librarian, Cranfield University.

Stephen, a well-respected and well-known speaker on the topic of benchmarking, provided an extensive overview of the topic with regard to academic library services. He opened the session by asking whether benchmarking could be regarded as strife, theft or commission. He believed it was much more clearly and positively related to curiosity, comparison and collaboration which was a much more natural process to human beings. He then provided the audience with two key definitions of benchmarking:-

'Benchmarking as one of twenty-one 'fads' or 'enthusiasms' constituting a logical whole, all of which are part of a broad wave of information driven [quality] management techniques which have swept through Western industry in the past two decades." Koenig, 2000

"Measurement and benchmarking are not separate sciences or unique theories of quality management, but rather strategic approaches to getting the best out of people, processes, products, plant and programmes.” John Oakland

\section{Workload}

Stephen moved on to examine, in more detail, the importance of benchmarking in the academic sector by first asking whether it was a marginal activity. In fact his studies clearly showed that at least $40 \%$ of all UK HE libraries were involved in some form of benchmarking. He then proceed to provide the seminar with individual and membership case studies:-

\section{UK 'Individual' Cases}

- Cranfield University RMCS Library (1993)

- Loughborough University BL Research (1995)

- Surrey Institute of Art \& Design (1997)

- Government \& Academic Libraries (1998)

- Cranfield RMCS Strategic Review (1998)

\section{UK 'Membership' Cases}

- SCONUL Pilots project (1997-) 
- Commonwealth University Management

- Benchmarking Club (Libraries 1998)

- 94 Group Libraries (1998)

\section{Case 1: Cranfield University RMCS Library (1993)}

Stephen outlined this benchmarking initiative which had been undertaken because of a requirement for competitive tendering within the government sector. In all 20 partners were brought together and the assessment of the critical success factors were achieved through qualitative and quantitative means. The outcomes proved that it was possible to identify best practice but it was not easy. The critical involvement and full understanding and participation of staff had proved challenging. It would, retrospectively, have been very useful to have process maps and unit costs but these had not been available. Nevertheless a great deal had been learnt and improvements were forthcoming.

\section{Case 2: “Loughborough” project. Loughborough University BL Research (1995)}

This BL funded project is available as a project report and had examined the quality context of benchmarking. It had produced some interesting conclusions including the clear identification of best practice by close attendance to standards; it had proved the very important part that process mapping plays in performance comparisons; to make the process worthwhile requires time, planning and effort including training overheads and finding that establishing clear ethics and confidentiality were key factors in success.

\section{Case 3: Surrey Institute of Art and Design (1997)}

This institutional project had taken a top down approach for which the library service had been the initial pilot. The initiative had included 4 partners, one of whom was non-library but provided a similar type of support to Advice desks. The overall outcomes had been the establishment of better practice overall. There had been challenges however particularly in planning, where the effort involved was substantial, and in the choice of partners for the project.

\section{Case 4: Government libraries IS (Government and Academic Libraries) (1998)}

The purpose of this project was to improve the overall IS management, particularly the provision of IT support. Of the 10 partners involved, three were academic. Much of the actual project planning, discussion and analysis had been undertaken by a consultant. The overall outcomes were that best practice had been clearly identifiable but that comparability measures had proved challenging, probably because of issues arising from confidentiality requirements.

\section{Case 5: Cranfield University Royal Military College Shrivenham Strategic Review} (1998) 
Stephen re-translated this into a "Conceptual Review" which examined strategic issues around buildings and electronic libraries. Whereas some of the work was undertaken through published sources, such as "vision" statements, other work was achieved via interviews and visits. Stephen felt that this particular example fulfils Watson's contention for libraries: "Benchmarking for strategic intent"

This methodology allowed best practice to be identified more simply and had the potential for use as an institutional learning style.

Stephen's interesting presentation moved onto an outline of the SCONUL

Benchmarking projects, which were established with the following objectives:-

- To provide practical experience

- To enlarge knowledge base

- To produce a standard methodology

- Create standard metrics

- Resources for facilitation \& results.

It comprised 7 Pilot projects, which Stephen briefly outlined.

- A1 Advice Desks (N)

- A2 Advice Desks (S)

- B1 Library Skills (N)

- B2 Library Skills (S)

- C Counter Services

- D Interlibrary Loans

- E Library Environment

The overall project had resulted in a SCONUL Benchmarking Manual 2000 for use by SCONUL institutions.

Stephen drew the following general conclusions from his review:

- Benchmarking is possible and desirable for those wanting to continually improve

- Needs quality and change management framework for follow through to work properly

- Methodology not problematic

- Measures very problematic but powerful when they work well

- There is a general willingness to engage with benchmarking by library profession

- Ethics are a barrier to take-up and publication

- Time and effort required

- Training

- Strategic level group approaches growing.

Before moving to his final section on Models and Methods, Stephen provided the seminar with an overview of the international perspective. In the United States there is minimal benchmarking activity in academic libraries. In Australia there was an extensive best practice initiative which had led to 41 different exercises up to 1998 . 
In Europe (outside of the UK) academic libraries in both Germany and Finland were actively exploring and implementing benchmarking.

\section{Models, Methods, Manuals}

In this final section Stephen outlined the Oakland methodology, with its 15-stage process.

\section{Stage Process (Oakland)}

- Plan

- Analyse

7 Stages

- Develop

3 Stages

- Improve

2 Stages

- Review

1 Stage

2 Stages

\section{Planning Stages}

- Select process groups

- Identify best competitor

- Identify benchmarks

- Bring together team

- Decide information and data-collection methodology

- Prepare for visits and interact with target organisations

- Use data-collection methodology.

\section{Action Stages}

- Compare using data

- Catalogue information

- Understand 'enabling processes

- Set new objectives/standards

- Develop action plans

- Implement actions and integrate

- Monitor results and improvements

- Review measures and relationship

He outlined the value of the SCONUL Benchmarking Manual 2000, which provides definitions and a context and models. It outlines a reduced three-phase, or sevenstage, methodology based around planning, comparing and acting.

He recommended the Benchmarking Audit methodology as definitely applicable to academic libraries and a powerful tool for analysis and improvement.

Stephen completed his comprehensive presentation by outlining what he viewed as future possibilities for benchmarking.

- The establishment of international benchmarking consortia

- The establishment of a national benchmarking clearing house

- Electronic benchmarking

- Benchmarking with external partners outside the sector.

\section{SCONUL: Statistics and Performance Indicators}


Ian Winkworth. Past Chair, SCONUL Advisory Committee on Performance Indicators. Formerly Director of Learning Resources, University of Northumbria at Newcastle.

The seminar particularly welcomed Ian who had agreed to attend and speak for LIRG despite his retirement less than a month previously. Ian provided an overview for his presentation which covered:

- SCONUL Statistics and performance measurement in 1995

- Progress between 1995-2000

- Current Developments.

\section{SCONUL and performance measurement 1995}

Ian summarised the position in 1995 as statistics and a bit more ... but not that much more!

- 30 years of statistics ... but for librarians (not actively used by senior management, government bodies etc.

- Statistical Analysis, presentation and interpretation under-developed

- No accepted conceptual framework for the sector

- Limited impact of statistics alone

He then moved on to discuss the development of a new conceptual framework: the Effective Academic Librarian (EAL), partly stemming from the brief provided by the Follett Report in 1993, to create a "coherent and generic" set of performance indicators. The EAL had taken a broad approach with 33 performance indicators split into five facets of performance. The response to EAL had been muted: Ian outlined a typical response as being: "There are too many indicators ... please add one on ..." A further fundamental influence of this time was the Teaching Quality Agency (TQA), that made libraries a key aspect of the "Learning Resources" TQA assessment. They key questions for libraries were:-

- Is there an overall learning resources strategy consistent with the course aspirations?

- Are the library services available, accessible and appropriate in terms of ... stock, study space, induction, opening hours, user support?

- Is there effective liaison with subject staff?

However TQA also provided SCONUL with an opportunity to lobby for better assessment of libraries with the production the useful SCONUL "aide memoire" as a script for assessors in local discussions.

\section{Progress 1995-2000}

Ian began this section of his presentation by outlining the work LISU (Library and Information Statistics Unit) had undertaken for SCONUL including:-

- Data input and data storage - "SCONUL 10-year Database"; 
- Data cleaning - to fill some gaps, correct obvious errors in the SCONUL data

- "Summary of Trends for SCONUL members" (1999);

- Customised statistical comparisons

- Statistical advice / guidance

- Data supply.

In 1997/98 there followed a one year funded research project led by Cranfield University which undertook the empirical testing of the quality of SCONUL data and the discrimination of possible performance indicators. The project proposed a "small set of recommended management statistics", which became the "UK Higher Education Library Management Statistics" (HELMS)

\section{UK Higher Education Library Management Statistics}

- Set of statistics chosen by a group of University and College Heads from Cranfield Study recommendations. This represented partial official recognition;

- All HE institutions covered in principle

- HESA (Higher Education Statistics Agency) data plus spreadsheet template

- Some new concepts - "Management statistics" separated from "Contextual Data"

- In second year graphics have now supplemented "boring old A-Z tables".

\section{Library Management Statistics}

- Input measures:

- Total library expenditure per FTE user

- Expenditure on information provision per FTE user

- Expenditure on staffing per FTE user

- Output Measures

- Seat hours offered per week per FTE user

- Loans per FTE user

(In future: Stock on loan; electronic services; user education)

- Inter-Library loans as \% of all loans

\section{Library contextual data}

- Number of libraries

- Space occupied

- Size of collection

- Number of seats

- Number of workstations

- Total library expenditure (at least 2 figures)

\section{Institutional contextual data}

- Number of students (FTE)

- $\%$ postgraduate students

- \% part-time students

- Number of academic \& research Staff

- Government research funding as a \% of all Government funding.

While there is provision for "hard" data on all physical resources, electronic services are a different matter. As forms of indicators were definitely required, SCONUL 
"contracted out" this issue to researchers funded from elsewhere such as the MIEL Project in 1998 and the EQUINOX European Project, 1999-2000.

The EQUINOX project was particularly interesting with 12 "electronic" indicators being tested such as the percentage of the population reached by electronic services, the number of "sessions" per head, and the cost per session or document.

\section{User Satisfaction Surveys - LIBRA Project 1998-1994}

The LIBRA project introduced new approaches by seeking to provide valid comparative data, new data collection methods, new presentation and the approach of actively working with a commercial agency, Priority Search. The methodology is based around a survey questionnaire which is then input using a digitiser tablet and light pen. The results and graphics are impressive. The benefits of the LIBRA approach include:

- Standard method for further testing

- Database of results for comparison

- Results discriminate, apparently sensibly, using small samples

- Interestingly one of the outcomes of work with the LIBRA approach has been the discovery that people who have used Academic / University libraries before came with slightly higher expectations.

Ian outlined a further possibility for development, which was outside the scope of the SCONUL project, which would be to concentrate on better services. He recommended using focus groups to devise statements which could then be grouped randomly in pairs to assess the relative importance to users of different improvements.

Ian went on to discuss the increasing complexity of the overall sectoral picture. Converged services meant that the concept of a standard "library" no longer existed and "library" elements are not easily disentangled. As already discussed there was increasing use of electronic services and the UCISA statistics. While SCONUL and UCISA had made some progress with the use of common definitions and approaches, their basic interest appeared to differ. The final challenge was the range of multiple stakeholders all with varying interests and requirements:-

- End-customers: students / staff

- Service purchasers: Academic Departments; Institutions

- Funders: Funding Councils; Government; the Taxpayer

- Guardians of quality: QAA, Professional bodies

- Service managers

- Staff.

\section{Current developments}

In his final section Ian began by outlining the future developments requested by SCONUL members in December 1999:- 
- Less data to send in

- More data about electronic services

- More support and guidance

- More automatic interpretation of the data.

SCONUL statistics took the following actions:

- 6-institution project on what data is difficult to collect and what data is used;

- LISU analysis of levels of response to current questions

- ACPI (Advisory Committee on Performance Indicators) review of content of SCONUL questionnaire.

A series of changes were proposed as follows:

- Draft 2000/2001 SCONUL questionnaire cuts data elements from 180 to 60;

- Data on electronic services included (Equinox, ISO)

- Overall shell of summary statistics unchanged

- Templates and guidance for local use

- Talk to library system suppliers.

The subsequent outcomes were currently under discussion but it was agreed that changes would be implemented for 2000/2001 submissions. There were also changes and developments in the presentation of information:-

- More trend analysis in annual volume HELMS: graphs before tables (next year include UCISA data?)

- How to present data for 180 libraries

- Spreadsheet files

- Web-mounted core data

- Proposed analysable database on web.

In addition to these developments SCONUL was also undertaking / promoting a range of performance measurement projects as follows:

- Promotion of benchmarking

- Promotion of LIBRA and User Satisfaction Survey Template

- ACPI website developed

- Libqual + trial (see below)

- Quality Model Framework for Performance Measurement (see below).

The ACPI web site was now available with a searchable statistics database.

Libqual was an ARL (American Research Libraries) initiative that had received an USA Federal grant. It was based on the SERVQUAL methodology and compares customer's view of perceived, desired and minimum service quality. It also offered a web-based questionnaire with instant submission, validation and analysis.

Finally the Quality Model Framework for Performance Measurement offered the following outline framework:- 
- Leadership (10\%)

- People management, Policy and strategy, Resources (3 x 9\%)

- Processes (14\%)

- People satisfaction (9\%), Customer satisfaction (20\%), Impact on society $(6 \%)$

- Business results (15\%)

\section{EAL/SCONUL references}

Joint Funding Councils Ad-hoc Group on Performance Indicators for Libraries. The Effective Academic Library: a framework for Evaluating the performance of UK academic Libraries. Bristol: Higher Education Funding Council for England, 1995

Standing Conference of National \& University Libraires. Annual Library Statistics 1998-99 London: SCONUL, 2000. ISSN 1352-1020

Creaser, Claire. Summary of Trends for SCONUL Members. Loughborough: LISU, 1999 [Internal Distribution to SCONUL]

UK Higher Education Library Management Statistics, 1998-99. London: SCONUL/HCLRG, 2000 ISBN 0900210222

Town, J. S. (ed.) SCONUL Benchmarking Manual. London: SCONUL, 2001

SCONUL User Satisfaction Project Report. London: SCONUL, 2001. http://www.sconul.ac.uk

\section{Background references}

Barton, Jane and Blagden, John. Academic Library Effectiveness: a comparative approach. Boston Spa: British Library Research and Innovation Centre, 1998. (British Library Research and Innovation Reports, 120)

Brophy, Peter and Coulling, Kate. Quality management for Information and library managers. London: Aslib, 1996 ISBN 0566077256

Crawford, John. The Stakeholder approach to the construction of performance measures: some implications. Library and Information Research News, 22 (170), 1998, p. 23-29. ISSN 0141-6561

Creaser, Claire and Murphy, Alison. LISU Annual Library Statistics 1999. Loughborough: LISU, 1999. ISSN 0967-487X

\section{SEMINAR OPEN SESSION}

Following the lunch break, seminar participants were invited to attend an open session where staff who were actively involved with a current Benchmarking Consortium were available to outline their work and provide an opportunity for participants to find out more from practitioners. This section of the seminar proved very popular. Open sessions were held on the following topics: 


\section{Activity Based Costing and Process Improvement}

Janet Weaver

Margaret Cadman

Anna Chapman

\section{Advice Desk}

Chris Martindale

Kathleen Morgan

Sarah Hall

\section{Staffordshire University}

Staffordshire University

Staffordshire University

University of Derby

Staffordshire University

Staffordshire University

\section{Weekend / evening operations}

Sue White

University of Huddersfield

\section{Short Loan Operations}

Janice Broad

Staffordshire University

Shelving Operations

Katherine Everest Leeds Metropolitan University

Lorraine Noel University of Huddersfield

The afternoon session commenced with a presentation from LISU.

\section{Contrasting figures: Using SCONUL Statistics vs. for comparative benchmarking}

Claire Creaser and J. Eric Davies

Library and Statistical Unit (LISU) Loughborough University

Eric Davies opened the presentation by stressing the importance of management information to the successful development of organisation of all kinds:-

Under the heading "Managing with meaning" he quoted: "Information is a precondition for identifying choices, reducing uncertainty about their implications and facilitating their implementation". (Center for Transnational Corporations:- CTC Reporter 14 Winter 1983 p. 34-).

Under the heading "Measuring with meaning" he quoted:

"Every organisation, no matter what its mission or scope needs three kinds of performance metrics -

- to measure its success in mobilizing its resources,

- its staff's effectiveness on the job, and

- its progress in fulfilling its mission."

He went on to discuss what he referred to as "Managing the Maze" comprising an array of elements: resources, users, materials, equipment, space, staff, funding. He further referred to "Managing the Music" even though the tunes sometimes differed slightly, with requirements stemming from a range of external agencies: HEFCE, TQA/QAA, RAE, Audit Commission and with other influences from across the sector 
coming from public libraries such as "Best value" and public library standards. From this followed an outline of the usefulness of purely statistical benchmarking providing:-

- Overview of performance

- Identifying comparators

- Trends over time

- Published data

- Limited to available data.

Before handing on to Claire, Eric then briefly outlined the services available from LISU such as:-

- Database of edited SCONUL returns

- consistent definitions

- estimates for missing data

- UK academic members only

- Tailor-made to customer requirements

- Independent commentary

- if required.

He was open about the limitations of this approach: it was broad brush; there were issues concerning data reliability and that often the outcomes raised more questions than answers. However, the questions themselves were often very valuable.

An important issue was the appropriate choice of comparator institutions. Claire listed the following options for choosing your comparators:

- Centrally chosen

- Geographic basis

- Library group

- Statistically comparable

- contextual data

- nearest neighbours analysis.

There was however a standard product available which included:

- Trends from 1991-92

- Graphic presentation

- Own figures, compared to:

- group average

- sector average

- all SCONUL members

- Independent commentary

- 6 carried out in 18 months.

From these graphical comparisons of key data, it was clearly possible to identify areas of concern and areas where further developments were required. Claire produced a 
series of graphical representations of data including "basket" comparison and "snapshot" analyses.

\section{Benchmarking agreements}

\section{Liz Hart, Director of Library and Learning Resources Service, Staffordshire University}

Liz outlined the issues around the creation of a benchmarking agreement between institutions using as an example the current and active agreement between the University of Derby, University Huddersfield, Leeds Metropolitan University and Staffordshire University. She regarded such formal agreements as essential because:-

- They provide a written commitment

- They ensured clarity of purpose which were:

- To produce beneficial cross University analysis of process, statistical information and service outcomes

- To produce comparative benchmarking data.

The grouping was also a voluntary one in the case outlined in which the equality of the partnership was emphasised. The agreement covered:

- Governance by an Executive Group;

- Operational Management:

- Operations Group:

- Ensuring consistency, comparative outcomes and methodology enhancements

- Operations sub group for each benchmarking area, led by one of the partner institutions

- Duration of the agreement clearly established

- Financial Commitments

- Ensuring an even workload and participation

- Get out clauses:

- Withdrawal with a minimum of 3 months notice

- Agreement to non-participation in specific projects due to local circumstances (for example, a new build);

Finally, and most importantly, was the written agreement on confidentiality. This formally agreed to openly share all information relevant to benchmarking even if it might be sensitive in nature. It is important to note that also included here was a separate clause concerning non-disclosure to external any other organisations or bodies. To date the agreement had worked well and provided a solid foundation for a fruitful partnership.

\section{Why had this example worked well?}

A number of important factors were outlined:-

- Experience of working together / Been in the SCONUL Benchmarking project

- Commitment of senior management 
- Commitment and enthusiasm of staff involved

- Active use of internal staff development and communication strategies for all staff

- Recognition that outcomes are very useful to improving / enhancing service delivery

- Politically advantageous - University senior management very impressed

- Side effects - lots!

- Excellent networking

- Staff development.

The seminar ended with a presentation from the Benchmarking partnership discussed by Liz in the previous presentation:-

\section{Benchmarking Shelving Processes}

Katherine Everest, Planning and Evaluation Manager, Leeds Metropolitan University Lorraine Noel, Site Services Manager, University of Huddersfield

The presentation included a brief introduction; an outline of techniques and tools, an overview of outcomes and themes and overall conclusions. Katherine and Lorraine provided some background to the benchmarking process including establishing the aims and objectives of their project. The techniques and tools provided were divided into the overall aim and the method employed in each case:-

\begin{tabular}{|c|c|}
\hline Shelving Times & \\
\hline Aim & Method \\
\hline $\begin{array}{l}\text { To record and measure the time taken to } \\
\text { re-shelve a returned book }\end{array}$ & $\begin{array}{l}\text { - tracking slips inserted in returned } \\
\text { books and removed when items } \\
\text { shelved } \\
\text { - times recorded }\end{array}$ \\
\hline \multicolumn{2}{|l|}{ Tidiness } \\
\hline Aim & Method \\
\hline $\begin{array}{l}\text { To measure the } \% \text { of items accurately } \\
\text { shelved in the whole sequence }\end{array}$ & $\begin{array}{l}\text { - shelf checks carried out at mid-point } \\
\text { of each classmark } \\
\text { - \% of incorrectly shelved items } \\
\text { recorded }\end{array}$ \\
\hline \multicolumn{2}{|l|}{ User Survey } \\
\hline Aim & Method \\
\hline $\begin{array}{l}\text { To measure whether users successfully } \\
\text { located items that they were looking for }\end{array}$ & $\begin{array}{l}\text { Questionnaires distributed to users } \\
\text { browsing shelves }\end{array}$ \\
\hline
\end{tabular}


A key element with all benchmarking is the establishment of environmental data. This allows comparisons between institutional processes which are not skewed by "local" factors. Environmental data used in this case study included:-

- Number of books returned during survey week

- Number of hours spent shelving and tidying during survey week

- 'Normal' staffing pattern for shelving operation

Both presenters commented on the cost-effective nature of the methods employed. This had facilitated ease of comparison. Equally the process had not been time consuming nor onerous to administer at any of the four institutions involved. The outcomes of the work had showed a great variation between institutions, some of which was explained when environmental data was applied.

\section{Shelving times}

The results of the Shelving Survey were as follows:

- Shelving Times:

- $18-145$ hours

- scale, staffing, layout (environmental data)

- Tidiness:

- $0 \%-36 \%$ out of place

- tidiness, shelving and other circulation duties

- User satisfaction survey:

- low levels of catalogue use, low success rate

The overall changes which had stemmed from an analysis of these outcomes were:

- Staffing patterns adjusted

- Staffing practices reviewed

- Shelving processes improved

- Integration of shelving processes

- User Support and Guidance.

In conclusion Katherine and Lorraine described benchmarking as very much a learning process. The advantage of partnership was the application of common goals which did not negate the usefulness of the outcomes to local applications. The methods employed had also proved practical, flexible and reusable. Finally they stressed the inclusiveness of the project for all four institutions and the collaboration, co-operation and innovation which had resulted. Services to users had definitely improved but there were of course many more questions arising!

What next? Well the partnership will repeat the project in 2001/2002 to provide series data and to check that changes which had resulted from last year's work are effective. Overall the presenters felt this project had provided successful, reusable, cost effective and flexible.

At the end of the seminar Biddy Fisher, Vice Chair of LIRG, thanked the participants for attending and the speakers for their valuable insights into performance 
measurement and benchmarking and to Staffordshire University for hosting the event on behalf of LIRG. 